\title{
Antimicrobial Peptides and Skin: A Paradigm of Translational Medicine
}

\author{
H.C. Korting ${ }^{a} \quad$ C. Schöllmann ${ }^{a} \quad$ M. Stauss-Grabo ${ }^{b} \quad$ M. Schäfer-Korting ${ }^{c}$ \\ ${ }^{a}$ Klinik und Poliklinik für Dermatologie und Allergologie der Ludwig-Maximilians-Universität München, München, \\ ${ }^{b}$ Engelhard Arzneimittel GmbH \& Co KG, Niederdorfelden, and ' Freie Universität Berlin, Institut für Pharmazie, \\ Berlin, Germany
}

\section{Key Words}

Antimicrobial peptides · Skin · Skin diseases - Tyrothricin • Translational medicine

\begin{abstract}
Antimicrobial peptides (AMPs) are small, cationic, amphiphilic peptides with broad-spectrum microbicidal activity against both bacteria and fungi. In mammals, AMPs form the first line of host defense against infections and generally play an important role as effector agents of the innate immune system. The AMP era was born more than 6 decades ago when the first cationic cyclic peptide antibiotics, namely polymyxins and tyrothricin, found their way into clinical use. Due to the good clinical experience in the treatment of, for example, infections of mucus membranes as well as the subsequent understanding of mode of action, AMPs are now considered for treatment of inflammatory skin diseases and for improving healing of infected wounds. Based on the preclinical findings, including pathobiochemistry and molecular medicine, targeted therapy strategies are developed and first results indicate that AMPs influence processes of diseased skin. Importantly, in contrast to other antibiotics, AMPs do not seem to propagate the development of antibiotic-resistant micro-organisms. Therefore, AMPs should be
\end{abstract}

tested in clinical trials for their efficacy and tolerability in inflammatory skin diseases and chronic wounds. Apart from possible fields of application, these peptides appear suited as an example of the paradigm of translational medicine for skin diseases which is today seen as a 'two-way road' - from bench to bedside and backwards from bedside to bench.

Copyright $\odot 2012$ S. Karger AG, Basel

\section{Introduction}

Antimicrobial peptides (AMPs) are also known as host defense peptides. More than 1,200 AMPs from different origins - bacteria, plants, insects, reptiles and mammals - have been reported [1-3]. The 'nature's antibiotics' form the first line of mammalian host defense against pathogens due to an important function as effector agents of the innate immune system [5]. Recent evidence suggests that AMPs also play an important role as signaling molecules in linking innate and adaptive immune responses $[6,7]$.

The small, cationic, amphiphilic peptides built up by 6-50 amino acids $[1,4]$ interact with anionic phospholipid membranes $[4,8]$ and thus show a broad-spectrum microbicidal activity against both bacteria and fungi [4].

\section{KARGER}

Fax +4161306 1234 E-Mail karger@karger.ch www.karger.com (c) 2012 S. Karger AG, Basel

$1660-5527 / 12 / 0256-0323 \$ 38.00 / 0$

Accessible online at:

www.karger.com/spp
Prof. Dr. Monika Schäfer-Korting

Institut für Pharmazie (Pharmakologie und Toxikologie)

Freie Universität Berlin, Königin-Luise-Strasse 2+4

DE-14195 Berlin (Germany)

Tel. +49 30838 53283, E-Mail Monika.Schaefer-Korting@fu-berlin.de 


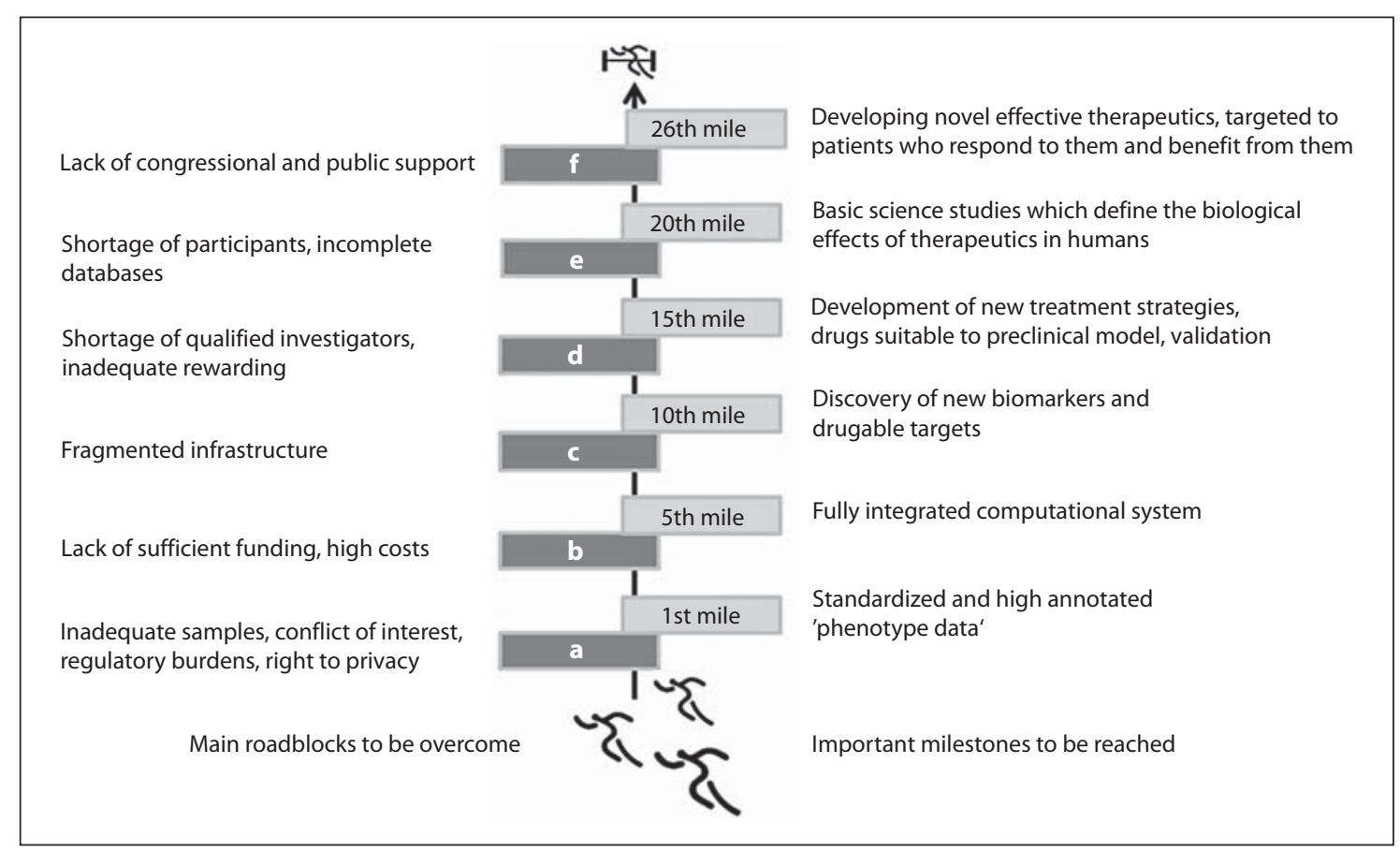

Fig. 1. Milestones of turning laboratory findings into therapy (modified from Kotlan et al. [14], with permission).

By directly targeting and destroying membranes even in multidrug-resistant pathogens [9], AMPs might contribute to overcoming the growing problems of antibiotic resistance $[1,9,10]$, and the shortage of new antibiotics to combat multidrug-resistant microbes has led to a new interest in AMPs at large and, in particular, to a renewed interest in older AMPs like polymyxins and tyrothricin [12]. In particular, AMPs as multifunctional agents [13] might provide new approaches in the management of infectious/inflammatory skin diseases and thus belong to the biggest hopes in curative dermatology.

AMPs are also well suited as an example of the paradigm of translational medicine, which means to introduce novel, effective therapeutic strategies in the clinic [14] by effectively translating basic research discoveries into clinical tools $[14,15]$. Thus, translational medicine is the interface between preclinical research and clinical development. The course of translational medicine was seen as a one-way street - with the goal of reaching the path 'from bench to bedside' as quickly as possible $[14,16]$ - although it soon became evident that the transfer of knowledge from the preclinical to the clinical grounds does not often function smoothly. This is partly due to the fact that even if preclinical research is being conducted on a large scale today, the results are sometimes ignored [16] and/or cannot be transferred from test tube or animal model to human diseases in real life [17]. Moreover, various regulatory obstacles and difficulties impede knowledge transfer ([14]; fig. 1). Recently, it has also been realized that new insights gained from observations on clinical grounds should flow back to the laboratory to develop new observation-based therapy strategies [14]. As a result, today, translational medicine is no longer seen as a one-way street but rather as a 'two-way road' - from bench to bedside and backwards from bedside to bench $[14,18]$.

From a chronological point of view, these two paths can also be seen in the development of AMPs for the treatment of skin diseases. For example, in the past, there already were individual peptides which, after their discovery and characterization, quickly and easily found their way from the laboratory to clinical application ('from bench to bedside') and today - decades after their identification - are still being used successfully. According to results of current investigations into molecular pathophysiology of skin diseases such as psoriasis, eczema or infected wounds, AMPs such as magainins isolated from African clawed frog Xenopus laevis and protecting the frog's skin against infections with bacteria 
and fungi, may allow the rear-entry path 'from bedside to bench' - from clinical back to preclinical investigations [19-22].

For other AMPs, researchers try to gain a better understanding of their role in the human skin and in skin diseases in advance to possibly be able to use their therapeutic potential in a targeted manner. As of today, it is already tempting to imagine that, in the future, the forward-looking 'from bench to bedside' path will become more important again. This is not only due to the fact that preclinical research activity in the area of skin diseases will continue to be more effectively organized, but also to the fact that all parties involved in the development of topical medicaments - basic scientists, pharmacologists, pharmacists, clinicians, ethic philosophers, patient advocates and not least the regulatory agencies - are working increasingly hand in hand today. As a result, many obstacles in the transfer from preclinical to clinical expertise tend to be removed during the preliminary stages.

\section{From Bench to Bedside: The Past}

Historically, the AMP era was born more than 6 decades ago when cationic cyclic peptide antibiotics, namely polymyxins and tyrothricin, were discovered and found their way into clinical application relatively quickly, though their modes of action were only uncovered years or even decades later. These AMPs had been somewhat forgotten as a result of the discovery of classical antibiotics such as penicillin before they currently began to experience a comeback in light of the increasing resistance problem vis-à-vis classical antibiotics and the extreme difficulty in developing truly novel antibiotics [23].

Polymyxins were discovered in 1947 in different species of Bacillus polymyxa [24]. Only two of them, polymyxin B and E (colistin), have been used in clinical practice. Polymyxins are pentabasic decapeptide antibiotics which contain a cycloheptapeptide ring with a C9 or C10 fatty acid chain through an $\alpha$-amide linkage. Polymyxins are active against Gram-negative bacteria such as Pseudomonas aeruginosa, Klebsiella pneumoniae, Acinetobacter baumannii and Enterobacter species even if they are multidrug-resistant. The target of antimicrobial activity is assumed to be the bacterial membrane, but there are also data supporting a multi-hit hypothesis. Polymyxins have also been shown to be an inhibitor of a single subunit $\mathrm{NADH}$ dehydrogenase (NDH-2) and quinol oxidases from certain bacteria making these AMPs promising chemotherapeutic agents [10]. As early reports described a high incidence of nephrotoxicity and neurotoxicity [25, 26], polymyxins were gradually withdrawn from clinical practice in the 1970s as newer antibiotics with the same or a broader antibacterial spectrum considered to be less toxic were introduced $[12,27]$. In recent years, we have observed a renewed interest in polymyxins supposedly due to AMPs' bactericidal activity even against multidrug-resistant bacteria by perturbing membrane integrity and due to actually less frequent and severe toxicity of polymyxins than originally reported. Moreover, a more careful dosing and the use of critical care services allows for risk control [27].

In clinical use, for decades also tyrothricin has gained particular interest for the topical treatment of superficial infectious skin wounds. Just as polymyxin, tyrothricin's potential was slightly underestimated over the years. Produced by Bacillus brevis [28], this polypeptide antibiotic consists of the two cyclic decapeptides, gramicidine $\mathrm{S}$ (22\%) and tyrocidine A (78\%) [29] (fig. 2), both peptides commanding broad bactericidal activity against Grampositive bacteria due to intercalation of the peptides into bacterial membranes. This leads to the formation of hydrophilic ion channels rapidly causing cell leakage and cell death [30]. The antimicrobial efficacy of tyrothricin seems to be the result of synergistic effects of tyrocidine (amino acids, purines, pyrimidines and phosphates) and gramicidine (increased potassium outflow) [31]. In addition, gramicidin disrupts vital functions of the bacterial cell by uncoupling the phosphorylation of the respiratory chain [31].

More recent publications have shown that tyrothricin in vitro shows a clinically relevant antibacterial activity against Gram-positive bacteria isolated from the normal flora of the respiratory tract with minimal inhibitory concentrations $\left(\mathrm{MIC}_{90}\right.$ ) ranging from $0.046 \mathrm{mg} / \mathrm{l}$ for Streptococcus pyogenes to $3.12 \mathrm{mg} / \mathrm{l}$ for Staphylococcus aureus, methicillin-susceptible (MSSA) and - particularly noteworthy - methicillin-resistant and multidrug-resistant strains of $S$. aureus [32, 33]. In vitro, tyrothricin is also active against streptococci including enterococci [32, 34] and yeasts like Candida albicans [35].

Besides its antibacterial activity, tyrothricin is also able to inactivate viruses like Sendai virus [36], herpes simplex virus (HSV) [37] and human immunodeficiency virus (HIV) [38]. Toxicity towards eukaryotic cells [39] restricts the use of tyrothricin as antibiotic to local application [40], in particular for the treatment of infected skin and infected oropharyngeal mucous membranes.

In the treatment of infectious small, superficial wounds, tyrothricin may find its place; also, resistance 


\begin{tabular}{|l|l|l|l|}
\hline Substance & Tyrothricin & Gramicidine \\
\hline $\begin{array}{l}\text { Structural } \\
\text { formula }\end{array}$ & \\
\hline $\begin{array}{l}\text { Molecular } \\
\text { weight }\end{array}$ & $1,228.44(\mathrm{~g} / \mathrm{mol})$ & $1,141.45(\mathrm{~g} / \mathrm{mol})$ \\
\hline $\begin{array}{l}\text { Empirical } \\
\text { formula }\end{array}$ & $\mathrm{C}_{65} \mathrm{H}_{85} \mathrm{~N}_{11} \mathrm{O}_{13}$ & $\mathrm{C}_{60} \mathrm{H}_{92} \mathrm{~N}_{12} \mathrm{O}_{10}$ & \\
\hline
\end{tabular}

Fig. 2. Tyrothricin, gramicidine and tyrocidine.

development to tyrothricin seems to be a rare event [34]. For example, the prolonged use of tyrothricin tooth paste over 2 years by 99 subjects neither led to an increase in the numbers of tyrothricin-resistant microorganisms nor to an increase in cross-resistance to penicillin, streptomycin, tetracyclines and chloramphenicol [41]. A recent study has demonstrated that Gram-positive bacteria including staphylococci and streptococci (including enterococci), as well as Corynebacterium spec. and yeast species, namely C. albicans and Candida parapsilosis, still turn out to be highly susceptible to tyrothricin, and susceptibility of formerly sensitive Gram-positive bacterial and yeast strains could be preserved over the years, indicating that the risk of resistance development against topically applied tyrothricin is negligible (unpublished data Engelhard). Microbiological data are in accordance with clinical data. In detail, the efficacy and tolerability of an antiseptic wound powder based on tyrothricin was demonstrated in a prospective, randomized multicenter trial with 131 patients with posttraumatic and surgical cutaneous lesions. Tyrothricin powder proved superior to vehicle concluding from the radius of the lesions $(\mathrm{p}=0.016)$ as well as the wound index ( $\mathrm{p}=0.005)$, while the tolerability of verum and vehicle did not differ [42]. Pertinent findings together with the lacking evidence for the development of resistance are reflected by the drug approval for topical formulations incorporating tyrothricin $0.1 \%$ (Tyrosur ${ }^{\circledR}$ Puder/Gel) for bacterially superinfected superficial wounds due to susceptible microorganisms. This is a good example of how an 'old' medicament can still be used and, in fact, is still being used today to treat skin diseases - even though initially the exact mode of action was not known.

\section{From Bedside to Bench: The Present}

Reflecting the good clinical experience with the use of 'old' AMPs such as tyrothricin and the subsequent understanding of their mechanisms of action, the potential of the 'natural antibiotics' at large has come into focus with respect to the treatment of infectious skin diseases. Owing to the significantly improved possibilities of molecular medicine, AMPs' immunomodulatory effects on the innate immune system and the adaptive immune response have been revealed, and AMPs thus might be used to treat inflammatory skin diseases at large and, in particular, to improve wound healing. Because of the new understanding of translational medicine as a 'two-way road' and because of the many regulatory obstacles and difficulties that currently stand in the way of a transfer of knowledge from the laboratory to the hospital [14], the 
first step in dermatology's approach today is understanding the role of AMPs in human skin. Based on these findings, targeted therapy strategies are developed which focus on the mechanism of action. In a third step, the insights gained in preclinical trials are supposed to be put into practice, and the AMPs that modulate the defined disease-related processes will have to be tested in clinical studies for their efficacy and tolerability. The current status of research, however, is an improved understanding of the physiological activity of AMPs in human skin and thus of their role in infectious and inflammatory skin diseases as well.

\section{AMPs in Invertebrate and Vertebrate Skin}

AMPs have been found in bacteria, invertebrates and vertebrates and show activity in organisms with or without complex adaptive immune system $[43,44]$. The observation that AMPs are locally produced in the epithelium after invertebrates like the moth Hyalophora cecropia, the fruit fly Drosophila melanogaster and at least 150 further insects $[43,45]$ have had contact with microbes supports the hypothesis that AMPs are part of a kind of primary 'chemical' defense system which - in addition to the physical barrier provided by the skin - protects interfaces from infection with pathogenic microorganisms. This hypothesis was supported in the late 1980s when the first inducible AMPs were isolated in vertebrates [19] for example the AMP magainin. It is secreted in the neuroepithelial glands of the frog's skin upon stimulation with noradrenalin [46]. Magainin commands a wide spectrum of antimicrobial activity against Gram-positive and Gram-negative bacteria and fungi [21], antiviral properties [47] and possibly anti-spermicidal activity [48]. Binding to anionic phospholipids on the outer leaflet of bacterial membranes, magainin leads to perturbation of membrane permeability and subsequently cell lysis [20,21, 49-52]. Today, magainins and their analogues are promising agents for future therapeutic approaches.

\section{AMPs in Human Skin}

Human skin is permanently exposed to microorganisms but rarely infected, thus showing a natural resistance towards pathogens. One, if not the main, reason for this might be the existence of constitutively and inducibly produced AMPs [43]. In fact, human skin is a major source of AMPs [44] with keratinocytes as the main producers [6] as cutaneous AMPs include the main groups of defensins, cathelicidins, dermcidin (DCD) and other small peptides such as neuropeptides and chemokines [44]. For several years, there has been a strong interest in better understanding the role of constitutively expressed and especially inducible AMPs in infectious/inflammatory diseases to determine their modes of action ('from bedside to bench') with the aim of being able, in the long run, to make targeted use of the therapeutic potential of these peptides in skin diseases ('from bench to bedside'). In the following section, we briefly present the most important human AMPs and subsequently shed light on their role in infectious/inflammatory skin diseases.

\section{Defensins}

Human defensins are AMPs of 30-40 amino acids with a molecular weight of about $3-4 \mathrm{kDa}$; six cysteines form intramolecular disulfide bonds [4]. Defensins can be classified as $\alpha$-, $\beta$ - and $\theta$-forms based on their typical spaces between the cysteine residues and their disulfide pattern. Neutrophils express $\alpha$-defensins [53], whereas keratinocytes are the source for $\beta$-defensins [6]. Up to now, six different human $\alpha$-defensins have been described: HPN (human neutrophil peptide)-1, HPN-2, HPN-3, HPN-4, as well as HD (human defensin)-5 and HD-6, with the latter two only being constitutively produced in Paneth cells (long-lived secretory cells) in the small intestine [54] and actively secreted in the urogenital tract; HD-5 is additionally expressed in female reproductive tissues [55]. To date, four different $\beta$-defensins expressed by keratinocytes have been identified and characterized: HBD (human $\beta$ defensin)-1 to -4 [44]. HBD-2 and -3 are highly induced by Gram-positive bacteria and inducibility of HBD-3 influences the severity of Grampositive skin infection [56]. $\theta$-defensins were primarily found in non-human primates [57] but have not been identified in humans so far.

Both $\alpha$ - and $\beta$-defensins show a broad antibacterial activity against Gram-positive and Gram-negative bacteria and also have antifungal and antiviral (adenovirus, papilloma virus, HIV and HSV) activity which derives from different modes of action including modulation of receptors on immunocompetent cells and inhibiting multiple steps of viral infectivity [44]. As with AMPs in general, the presumed mechanism of bacterial killing is binding of positively charged defensins to negatively charged bacterial membranes resulting in membrane permeabilization [44].

\section{Cathelicidin}

Cathelicidin peptides, including the human cathelicidin LL-37, mostly form an $\alpha$-helical structure; cationic charge enables these AMPs to bind to negatively charged bacterial membranes [44]. In humans, only cathelicidin 
LL-37 is expressed by neutrophils, mast cells and keratinocytes (after an inflammatory stimulus) as the major sources [6]. LL-37 shows a broad activity against Grampositive and Gram-negative bacteria and works synergistically with other AMPs like $\beta$-defensins [58]. Besides its antimicrobial effect, LL-37 is able to chemoattract mast cells, neutrophils, monocytes and $\mathrm{T}$ cells to sites of inflammation and additionally modulates immune responses and re-epithelization of skin wounds [59], making LL-37 an interesting peptide for therapeutic intervention in infectious/inflammatory diseases [60].

\section{Dermcidin}

DCD was identified in the eccrine gland and appears to be the principal sweat AMP [61]. Other than defensins and cathelicidins, DCD is constitutively secreted in human sweat and is not inducible by injury and dermal inflammation [62]. Proteolytic cleavage of a $9.3-\mathrm{kDa}$ precursor results in a peptide made of 47 amino acids (DCD1) which - in low micromolar concentrations - shows antimicrobial activity against $S$. aureus, Enterococcus faecalis, Escherichia coli and C. albicans under in vitro conditions resembling human sweat [61]. Contrary to defensins and cathelicidins, DCD-1 most likely does not kill bacteria by permeabilizing their membranes as DCD-1 is an anionic peptide showing a flexible structure with $\alpha$-helices and $\beta$-sheets, depending on the environmental conditions [63]. The amount of DCD-1 in human sweat, which is $1-10 \mu \mathrm{g} / \mathrm{ml}$ in healthy humans [61], appears to be reduced in patients with atopic dermatitis [43].

\section{Other AMPs}

Besides defensins, cathelicidins and DCD, human skin expresses other AMPs such as proteinase inhibitors, chemokines and neuronal proteins/peptides with RNase 7 and psoriasin (S100A7) as the most prominent representatives [44]. The highly basic $14.5-\mathrm{kDa}$ protein RNase 7 [64] is one of the major heparin-binding proteins in healthy human stratum corneum [43]. In addition to its relative abundance in human skin, the expression of RNase 7 can further be induced by proinflammatory cytokines and possibly by bacteria $[64,65]$. RNase 7 from human skin shows a broad activity against Gram-negative (E. coli and P. aeruginosa) and Gram-positive bacteria (Propionibacterium acnes and S. aureus) as well as against the yeast C. albicans [44]. In this sense, RNase 7 is one of the most potent and most efficacious human antimicrobial proteins known so far [43]. Recently, another member of the RNase family, RNase 8 , has been identi- fied as a novel AMP with broad-spectrum microbicidal activity [66].

Psoriasin is a calcium- and zinc-binding peptide that is expressed in healthy skin stratum corneum $[44,67]$ and in even higher amounts in psoriatic skin [68]. Psoriasin is the principal E. coli-bactericidal component and one of the innate barriers of healthy skin; $P$. aeruginosa and $S$. aureus are less susceptive $[43,44,67]$.

\section{AMPs in Skin Diseases}

What makes AMPs especially interesting for applied dermatology is the relation between the severity of various skin diseases and the expression of AMPs. Correlations can be positive or inverse $[6,44]$. For example, there is an association between lowered levels of AMPs in burns as well as chronic wounds compared to normal skin. A reduced amount of DCD in the sweat coincides with an impaired innate defense of human skin, while AMP overexpression in human skin appears to be accompanied by an increased protection against infection in psoriasis, rosacea or in other inflammatory skin diseases [6]. These findings indicate that AMPs have a potential for therapeutic use. Before practical use, however, the role of a particular peptide in various skin diseases should be precisely known.

\section{AMPs and Psoriasis}

Psoriasis is an inflammatory non-infectious skin disease with typical inflammatory plaques reflecting hyperproliferation of the epidermis resulting in massive production of scale $[6,69]$. Psoriasis is considered to be an autoimmune disease as in psoriatic lesions, high levels of proinflammatory cytokines, chemokines as well as activated $\mathrm{T}$ cells and antigen-presenting cells can be found. Interestingly, in the skin of patients with psoriasis, almost all known AMPs, such as the $\beta$-defensins HBD- 2 and -3 , the cathelicidin LL-37, psoriasin, RNase 7 as well as other AMPs (such as ALP/SLP1, Elafin/SKALP), are highly upregulated $[6,65]$ (see also fig. 3). The overexpression of AMPs accompanied by the synergistic interaction seems to be one major reason for the observed lowered susceptibility of psoriatic skin to cutaneous bacterial infections [70].

Although the mechanism of AMP induction in psoriatic skin is not completely understood, there seems to be a strong association with increased levels of cytokines like IL-1 $\beta$ and IL- 6 , as well as IFN- $\alpha$ and $-\gamma[11,71-74]$. This hypothesis is supported by cathelicidin LL-37 induction of IFN- $\alpha$ [75]. 


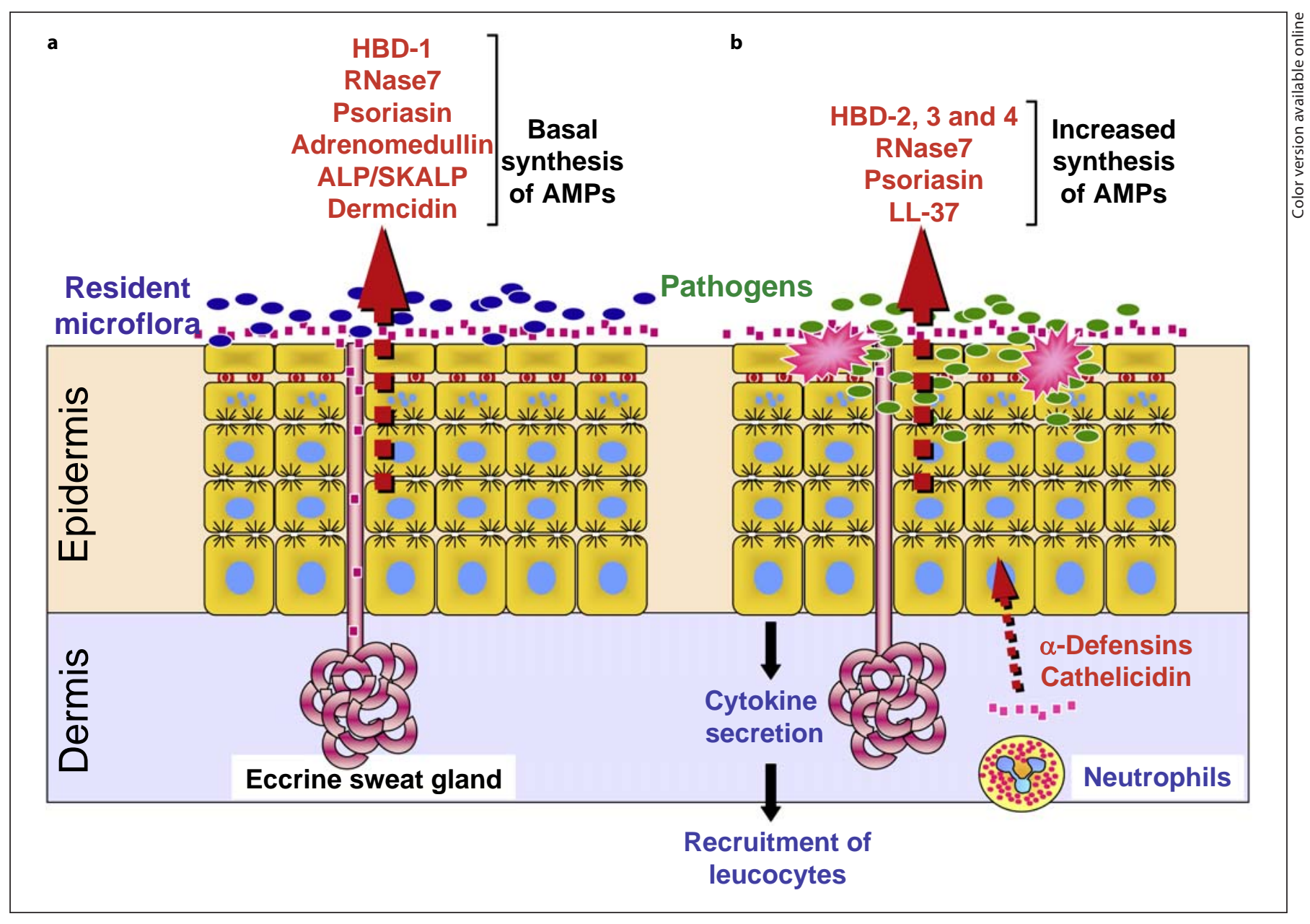

Fig. 3. Illustration of the protective function of AMPs in normal skin (a) and infected and/or inflamed skin such as in psoriasis (b) (from Schittek et al. [6], with permission).

\section{AMPs and Rosacea}

Rosacea is a common chronic, often underdiagnosed, skin disease of uncertain etiology. The various clinical manifestations associated with this disease most frequently occur in the light-skinned Caucasian population, in persons between 30 and 50 years of age $[76,77]$. The dermatological manifestations of rosacea mainly affect cheek, nose, chin, and central forehead. The earliest symptoms associated with rosacea are intermittent central facial flushing and erythema. Furthermore, the disease may be linked to ocular manifestations [78]. Until today, the pathogenesis of rosacea is not known in detail, yet evidence has been accumulating that rosacea with its common symptoms, such as inflammatory lesions, erythema, teleangiectasia, phy- matous changes and ocular symptoms, is of inflammatory nature [79].

Most recently, it could be shown that symptoms of rosacea are exacerbated by factors that trigger innate immune responses, such as the release of cathelicidin AMPs produced by keratinocytes [80]. Clearly, there is a role of cathelicidin in skin inflammatory responses as individuals with rosacea express cathelicidin LL-37 at abnormally high levels in their facial skin, and specific proteolytically processed forms of cathelicidin peptides found in rosacea differ from those found in normal individuals $[79,81]$. These forms, but not those from healthy skin, are able to induce the release of the proinflammatory IL-8 from keratinocytes [6]. This means that in the pathogenesis of rosacea, cathelicidin peptides likely are abnormal- 
ly processed to forms that induce inflammation [7], providing evidence that the elevated levels of cathelicidins contribute to the chronic inflammatory reaction in the skin of patients with rosacea [6].

\section{AMPs and Acne Vulgaris}

Acne vulgaris is a chronic inflammatory disorder of the pilosebaceous units widely affecting adolescents and young adults. Characteristic of this skin disorder is the formation of comedones, papules, pustules, nodules and/ or cysts as a result of obstruction and inflammation. The pathogenesis, as far as already known, involves excess sebum production, follicular hyperproliferation, inflammatory reactions and colonization with $P$. acnes [82]. In lesional and perilesional epithelium of patients with acne vulgaris, a marked upregulation of human $\beta$-defensins (HBD-1 and HBD-2) is found, in the case of HBD-2 most likely triggered by $P$. acnes and mediated by the Toll-like receptor (TLR) signaling pathway [83]. The role of other AMPs remains to be clarified, but it is known that $\beta$-defensins, cathelicidin LL-37 and psoriasin expressed in keratinocytes and sebocytes are able to kill $P$. acnes making these AMPs possible future candidates for therapeutic intervention oriented at the pathogenesis of acne. Another AMP interesting for the future treatment of acne is omiganan, a novel, synthetic, cationic analogue of the AMP indolicidin that was originally purified from the cytoplasmic granules of bovine neutrophils [84]. It demonstrates in vitro activity against a wide variety of microorganisms, including Gram-positive and Gram-negative bacteria and fungi [84]. Omiganan is the most advanced agent in the frontline of applications of AMPs [85] and is currently clinically tested for the treatment of acne and rosacea.

\section{AMPs and Atopic Dermatitis}

Atopic dermatitis is a complex chronic inflammatory skin disease which is characterized by xerosis, pruritus (itch) and erythematous lesions with increased transepidermal water loss [86]. Atopic dermatitis significantly affects the quality of life of patients and their families. New insights into the pathophysiology of the disease refer to an important role of structural abnormalities in the epidermis associated with immune dysregulation [87]. Typically, patients with atopic dermatitis show a predisposition to colonization or infection by various microorganisms, in particular S. aureus and HSV A [87]. Some studies analyzing AMPs in lesional skin show that, in contrast to psoriasis, rosacea and acne vulgaris, atopic dermatitis is characterized by less expression of AMPs, especially of cathelicidin LL-37 and HBD-2 [72, 88, 89]. It has been hypothesized that a reduced induction of AMPs in atopic dermatitis may contribute to the increased susceptibility of skin infections, in particular with $S$. aureus $[72,90]$. However, most of the studies investigating AMP expression levels in atopic dermatitis skin have compared these levels primarily to those in psoriatic skin, not to healthy skin [72, 88, 89]. Gläser et al. [91] observed that the expression and secretion of psoriasin was more strongly induced in atopic dermatitis skin compared to healthy skin, indicating that AMP expression is not generally reduced in atopic dermatitis. An enhanced expression of RNase 7, psoriasin and HBD-2 and HBD-3 in atopic dermatitis lesional skin compared to non-lesional skin and healthy controls is possibly triggered by a disturbed skin barrier. Thus, the role of AMPs in atopic dermatitis, especially with regard to the control of $S$. aureus colonization, remains to be elucidated in more detail [92].

AMPs and Skin Injury/Wounds

The functional role of constitutively and inducibly expressed AMPs after skin injury and in chronic wounds also needs further analysis. At present, data from the literature suggest that AMPs, such as cathelicidin LL-37, HBD-2, HBD-3, psoriasin and RNase 7, are upregulated after skin injury, including burnt skin [5, 21, 44], whereas cathelicidin expression is low or even absent in the chronic wound stage $[6,44]$. As LL-37 has a direct effect on wound healing by promoting neovascularization and angiogenesis $[5,93]$, this AMP seems to be the most promising agent for future therapeutic approaches in order to antagonize impaired wound healing.

\section{AMPs and Other Skin Diseases}

There are also other skin diseases with an altered AMP expression, but pertinent data are somewhat fragmentary and not completely consistent as yet. In general, inflammatory skin diseases seem to be associated with an increased expression of AMPs. For example, HBD-2 has been shown to be upregulated in superficial folliculitis [94] and HBD-1 to HBD-3 mRNA levels in localized scleroderma [95]. High expression of HPN-3 has been found in cutaneous T-cell lymphoma patients [96]. Condyloma acuminatum and verruca vulgaris are associated with an increase in cathelicidin LL-37 expression [97]. Altogether, the precise function of AMPs in the mentioned skin diseases, however, remains to be further clarified. 


\section{From Bench to Bedside: The Future}

On the basis of the new insights into the cellular and molecular roles of AMPs in human skin and in certain skin diseases described above, it is to be expected that a second wave of new 'from bench to bedside' AMPs will contribute to our therapeutic armamentarium within a few years [23].

Several AMPs are currently undergoing laboratory testing and the application of these peptides in in vitro experiments and animal models is seemingly successful [45]. However, despite undeniable successes in the preclinical area, only few AMPs have reached the phase of testing in clinical trials so far $[45,98,99]$. At present, four AMPs were successful in therapeutic clinical trials [5]. Pexiganan, a derivative of magainin, which has been developed for the treatment of infected foot ulcers in patients with diabetes mellitus and which entered phase III trials [45] and has been shown to be equally effective as oral ofloxacin, was finally not approved by the US Food and Drug Administration [98]. Omiganan has completed one phase II study for the treatment of rosacea and two phase II studies for the treatment of acne, the latter demonstrating evidence of efficacy against all acne lesion types [100]. One possible reason for the fact that clinical studies and, even more so, the large phase III studies with AMPs are very rare is the still limited knowledge on stability of peptides, although stability problems can be largely overcome by adding protease inhibitors [45]. A possibly even more important reason that so few AMPs have been clinically tested up to now appears to be a possible cytotoxicity of AMPs $[45,101]$. For example, the mammalian AMP protegerin-1 reduced the bacterial count in a murine sepsis model, yet it also reduced the survival rate - probably by inducing endotoxin release and, as a result, modifications in the host innate immune response [102].

Despite the problems of cytotoxicity of AMPs, in topical treatment of skin diseases, they are certainly less significant than in the systemic therapy of infectious and/or inflammatory diseases. However, it is important to mention in this regard that, although tyrothricin can only be administered topically because of its systemic toxicity, it is still effective and well tolerated in the therapy of skin disease. Recently, strategies have increasingly been devised aiming at a reduced cytotoxicity of AMPs and, if possible, at the same time at an improved antimicrobial activity [5].

One of these strategies is to make designer peptides such as P-novispirin G10 [103]. They exhibit low cyto- toxic activity and often at the same time show an improved therapeutic efficacy, as it has been shown for a bactericidal immunomodulatory fusion peptide of HBD3 with a mannose-binding lectin, even against MRSA [104]. Another promising strategy is to develop analogues or truncated molecules of human AMPs, e.g. of cathelicidin LL-37, being less hemolytic and toxic as well as more effective compared to native LL-37 [105, 106]. Finally, some scientists substitute several L-amino acids in AMPs to achieve a reduced toxicity [107] or combine conventional antibiotics with AMPs in order to ensure high antimicrobial activity and low toxicity $[5,108]$ while at the same time reducing the risk of bacterial resistance. Although it cannot as yet be said which of these strategies will ultimately succeed and will help to bring new AMPs or their derivatives to the clinic to treat infectious and/or inflammatory skin diseases, the fact remains that intensive work is being done on these issues worldwide.

\section{Conclusion}

Based on new insights into the cellular and molecular roles of AMPs in human skin and in infectious/inflammatory skin diseases, it is to be expected that AMPs or their recombinant analogues will contribute to our therapeutic armamentarium within a few years. Strategies have increasingly been devised aiming at a reduced cy totoxicity of AMPs and ideally at the same time at an improved antimicrobial activity. Nevertheless, presently 'old' AMPs, such as tyrothricin, are still of clinical importance in the treatment of infectious skin diseases and may experience a renaissance as natural antibiotics.

\section{Disclosure Statement}

The preparation of this paper was supported by an educational grant from Engelhard Arzneimittel GmbH \& Co KG, Niederdorfelden, Germany, to C.S; H.C.K. collaborates with Engelhard Arzneimittel in the development of topical drugs for skin diseases. M.S.-G. is employed by the company that supported this investigation but does not have any personal financial interest in the research described in the paper. Data analysis and interpretation were not influenced by the company. H.C.K. and M.S.-K. are principal investigators of the EU-funded research project 'Nanoskin'. 


\section{References}

1 Wang Z, Wang G: APD: the Antimicrobial Peptide Database. Nucleic Acids Res 2004; 32:590-592.

2 Maroti G, Kereszt A, Kondorosi E, Mergaert P: Natural roles of antimicrobial peptides in microbes, plants and animals. Res Microbiol 2011;162:363-374.

3 Wang G, Li X, Wang Z: APD2: the updated antimicrobial Peptide Database and its application in peptide design. Nucleic Acids Res 2009;37:933-937.

4 Schneider JJ, Unholzer A, Schaller M, Schäfer-Korting M, Korting HC: Human defensins. J Mol Med 2005;83:587-595.

5 Steinstraesser L, Koehler T, Jacobsen F, Daigeler A, Goertz O, Langer S, Kesting M, Steinau H, Eriksson E, Hirsch T: Host defense peptides in wound healing. Mol Med 2008; 14:528-537.

6 Schittek B, Paulmann M, Senyürek I, Steffen $\mathrm{H}$ : The role of antimicrobial peptides in human skin and skin infectious diseases. Infect Disord Drug Targets 2008;8:135-143.

7 Schauber J, Gallo RL: Antimicrobial peptides and the skin immune defense system. J Allergy Clin Immunol 2008;122:261-266.

8 Khandelia H, Ipsen JH, Mouritsen OG: The impact of peptides on lipid membranes. Biochim Biophys Acta 2008;1778:1528-1536.

9 Hancock RE, Patrzykat A: Clinical development of cationic antimicrobial peptides: from natural to novel antibiotics. Curr Drug Targets Infect Disord 2002;2:79-83.

10 Bradshaw J: Cationic antimicrobial peptides: issues for potential clinical use. BioDrugs 2003; 17:233-240.

11 Guiliani A, Pirri G, Nicoletto SF: Antimicrobial peptides: an overview of a promising class of therapeutics. Centr Eur J Biol 2007;2: 1-33.

12 Mogi T, Kita K: Gramicidin S and polymyxins: the revival of cationic cyclic peptide antibiotics. Cell Mol Life Sci 2009;66:38213826.

13 Lai Y, Gallo RL: AMPed Up immunity: how antimicrobial peptides have multiple roles in immune defense. Trends Immunol 2009;30: 131-141.

14 Kotlan B, Stroncek DF, Maricola FM: Turning laboratory findings into therapy: a marathon goal that has to be reached. Pol Arch Med Wewn 2009; 119:586-593.

15 Jung K, Mannello F, Lein M: Translating molecular medicine into clinical tools: doomed to fail by neglecting basic preanalytical principles. J Transl Med 2009;7:1-4.

16 Plebani M, Marincola FM: Research translation: a new frontier for clinical laboratories. Clin Chem Lab Med 2006;44:1303-1312.

17 Nussenblatt RB, Marincola FM, Schechter AN: Translational medicine - doing it backwards. J Transl Med 2010;8:12.

18 Marincola FM: Translational medicine: a two-way road. J Transl Med 2003;1:1-2.
19 Zasloff M: Magainins, a class of antimicrobial peptides from Xenopus skin: isolation, characterization of two active forms, and partial cDNA sequence of a precursor. Proc Natl Acad Sci USA 1987;84:5449-5453.

20 Jacob L, Zasloff M: Potential therapeutic applications of magainins and other antimicrobial agents of animal origin. Ciba Found Symp 1994;186:197-216.

21 Ge Y, MacDonald D, Henry MM, Hait HI, Nalson KA, Lipsky BA, Zasloff MA, Holroyd KJ: In vitro susceptibility to pexiganan of bacteria isolated from infected diabetic foot ulcers. Diag Microb Infect Dis 1999;35:4553.

22 Zairi A, Tangy F, Bouassida K, Hani K: Dermaseptins and magainins: antimicrobial peptides from frogs' skin - new sources for a promising spermicides microbicides - a mini review. J Biomed Biotechnol 2009;2009: 452567.

23 Kruse T, Kristensen HH: Using anti-microbial host defense peptides as anti-infective and immunomodulatory agents. Expert Rey Anti Infect Ther 2008;6:887-895.

24 Storm DR, Rosenthal KS, Swanson PE: Polymyxin and related peptide antibiotics. Annu Rev Biochem 1977;46:723-763.

25 Brown JM, Dorman DC, Roy LP: Acute renal failure due to overdosage of colistin. Med J Aust 1970;2:923-934.

26 Koch-Weser J, Sidel VW, Federman EB, Kanarek P, Finer DC, Eaton AE: Adverse effects of sodium colistimethate. Manifestations and specific reaction rates during 317 courses of therapy. Ann Intern Med 1970;72: 857-868.

27 Falagas ME, Kasiakou SK: Toxicity of polymyxins: a systematic review of the evidence from old and recent studies. Crit Care 2006; 10:R27.

28 Dubos RJ, Cattaneo C: Studies on a bactericidal agent extracted from a soil bacillus. J Exp Med 1939;70:249-256.

29 Franklin TJ, Snow GA (eds): Biochemistry of Antimicrobial Action. New York, Chapman and Hall, 1988, pp 61-64.

30 Seoh SA, Busath D: The permeation properties of small organic cations in gramicidin A channels. Biophys J 1993;64:1017-1028.

31 Voigt HU, Ehlers G: Tyrothricin: Renaissance eines Lokalantibiotikums Teil I. Dtsch Dermatolog 1989;37:647-650.

32 Kretschmar M, Nichterlein T, Hof H, Burger KJ: Tyrothricin. Bakterizide Wirkung auf fakultativ pathogene grampositive aerobe Bakterien der Mundflora und MRSA. Chemother J 1995;4:156-159.

33 Kretschmar M, Witte W, Hof H: Bacterial activity of tyrothricin against methicillin resistant Staphylococcus aureus with reduced susceptibility to mupirocin. Eur J Microbio Infect Dis 1996;15:261-263.
34 Ruckdeschel G, Beaufort F, Nahler G, Belzer $O$ : In vitro antibacterial activity of gramicidin and tyrothricin. Arzneimittelforschung 1983;33:1620-1622.

35 Kretschmar M, Nichterlein T, Nebe CT, Hof $\mathrm{H}$, Burger KJ: Fungicidal effect of tyrothricin on Candida albicans. Mycoses 1996;39:4550 .

36 Grossgebauer K, Hartmann D: Antiviral activity of tyrothricin against Sendai virus in suspension tests. Zentralbl Bakt, Parasitenkunde, Infektionskrankheiten und Hygiene, Reihe B 1978;166:434-442.

37 Hartmann D, Grossgebauer K: Schutzversuche mit Tyrothricin an der Herpes-simplex-Virus-infizierten Maus. Arzneimittelforschung 1979;29:50-54.

38 Bourinbaiar AS, Krasinski K, Borkowsky W: Anti-HIV effect of gramicidin in vitro: potential for spermicide use. Life Sci 1994;54: 5-9.

39 Muramatsu I, Sofuku S, Hagitani A: A new synthetic and antibiotic analog of gramicidin S, (4-5-aminovaleric acid)-gramicidin S. J Antibiot Tokyo 1972;25:189-190.

40 Willenberg W: Zur Therapie akutentzündlicher Erkrankungen des Mund- und Rachenraumes. Zeitschr Allgemeinmed 1979;55: 653-655.

41 Lind HE, Swanton EM: Antibiot Chemother 1954;4:1161. Cited from Ruckdeschel G, Beaufort F, Nahler G, Belzer O: In vitro antibacterial activity of gramicidin and tyrothricin. Arzneimittelforschung 1983;33:16201622.

42 Bayerl C, Völp A: Tyrothricin powder in the treatment of cutaneous lesions. Pharmazie 2004;59:864-868.

43 Schröder JM, Harder J: Antimicrobial skin peptides and proteins. Cell Mol Life Sci 2006; 63:469-486.

44 Yamasaki K, Gallo RL: Antimicrobial peptides in human skin disease. Eur J Dermatol 2008; 18:11-21.

45 Reddy KVR, Yedery RD, Aranha C: Antimicrobial peptides: premises and promises. Int J Antimicrob Agents 2004;24:536-547.

46 Simmaco M, Mignogna G, Barra D: Antimicrobial peptides from amphibian skin: what do they tell us? Biopolymers 1998;47:435450

47 Albiol Matanic VC, Castilla V: Antiviral activity of antimicrobial cationic peptides against Junin virus and herpes simplex virus. Int J Antimicrob Agents 2004;23:382-389.

48 Reddy KVR, Shahani SK, Meherij PK: Spermicidal activity of magainins: in-vitro and in-vivo studies. Contraception 1996;53:205210.

49 Imura Y, Choda N, Matsuzaki K: Magainin 2 in action: distinct modes of membrane permeabilization in living bacterial and mammalian cells. Biophys J 2008;95:5757-5765. 
50 Gregory SM, Pokorny A, Almeida PFF: Magainin 2 revisited: a test for the all-ornone permeabilization of phospholipid vesicles. Biophys J 2009;96:116-131.

51 Epand RF, Maloy WL, Ramamoorthy A, Epand RM: Probing the 'charge cluster mechanism' in amphipathic helical cationic antimicrobial peptides. Biochemistry 2010; 49:4076-4084.

52 Dempsey CE, Hawrani A, Howe RA, Walsh TR: Amphipathic antimicrobial peptides from biophysics to therapeutics? Protein Pept Lett 2010;17:1334-1344.

53 Huttner KM, Bevins CL: Antimicrobial peptides as mediators of epithelial host defense. Pediatr Res 1999;45:785-794.

54 Mallow EB, Harris A, Salzman N, Russell JP, DeBerardinis RJ, Ruchelli E, Bevins CL: Human enteric defensins. Gene structure and developmental expression. J Biol Chem 1996; 271:4038-4045.

55 Svinarich DM, Gomez R, Romero R: Detection of human defensin 5 in reproductive tissues. Am J Obstet Gynecol 1997;176:470475.

56 Zanger P, Holzer J, Schleucher R, Scherbaum H, Schittek B, Gabrysch S: Severity of Staphylococcus aureus infection of the skin is associated with inducibility of human beta-defensin 3 but not human beta-defensin 2 . Infect Immun 2010;78:3112-3117.

57 Tang YQ, Yuan J, Osapay G, Osapay K, Tran D, Miller CJ, Ouellette AJ, Selsted ME: A cyclic antimicrobial peptide produced in primate leukocytes by the ligation of two truncated alpha-defensins. Science 1999;286: 498-502.

58 Carretero M, Del Río M, García M, Escámez MJ, Mirones I, Rivas L, Balague C, Jorcano JL, Larcher F: A cutaneous gene therapy approach to treat infection through keratinocyte-targeted overexpression of antimicrobial peptides. FASEB J 2004;18:1931-1933

59 Pivarcsi A, Nagy I, Koreck A, Kis K, Kenderessy-Szabo A, Szell M, Dobozy A, Kemeny L: Microbial compounds induce the expression of pro-inflammatory cytokines, chemokines and human beta-defensin-2 in vaginal epithelial cells. Microbes Infect 2005;7:11171127.

60 Nijnik A, Hancock RE: The roles of cathelicidin LL-37 in immune defences and novel clinical applications. Curr Opin Hematol 2009; 16:41-47.

61 Schittek B, Hipfel R, Sauer B, Bauer J, Kalbacher H, Stevanovic S, Schirle M, Schroeder K, Blin N, Meier F, Rassner G, Garbe C: Dermcidin: a novel human antibiotic peptide secreted by sweat glands. Nat Immunol 2001;2:1133-1137.

62 Rieg S, Garbe C, Sauer B, Kalbacher H, Schittek B: Dermcidin is constitutively produced by eccrine sweat glands and is not induced in epidermal cells under inflammatory skin conditions. Br J Dermatol 2004;151:534-539.
63 Lai YP, Peng YF, Zuo Y, Huang J, Wang LF, Wu ZR: Functional and structural characterization of recombinant dermcidin-1L, a human antimicrobial peptide. Biochem Biophys Res Commun 2005;328:243-250.

64 Harder J, Schröder JM: RNase 7, a novel innate immune defense antimicrobial protein of healthy human skin. J Biol Chem 2002; 277:46779-46784.

65 Harder J, Schröder JM: Psoriatic scales: a promising source for the isolation of human skin-derived antimicrobial proteins. J Leukoc Biol 2005;77:476-486.

66 Rudolph B, Podschun R, Sahly H, Schubert S, Schröder JM, Harder J: Identification of RNase 8 as a novel human antimicrobial protein. Antimicrob Agents Chemother 2006; 50:3194-3196

67 Glaser R, Harder J, Lange H, Bartels J, Christophers E, Schroeder JM: Antimicrobial psoriasin (S100A7) protects human skin from Escherichia coli infection. Nat Immunol 2005;6:57-64.

68 Madsen $\mathrm{P}$, Rasmussen $\mathrm{HH}$, Leffers $\mathrm{H}$, Honore B, Dejgaard K, Olsen E, Kiil J, Walbum E, Andersen AH, Basse B, et al: Molecular cloning, occurrence, and expression of a novel partially secreted protein 'psoriasin' that is highly up-regulated in psoriatic skin. J Invest Dermatol 1991;97:701-712.

69 Schön MP, Boehncke WH: Psoriasis. N Engl J Med 2005;352:1899-1912.

70 Christophers E, Henseler T: Contrasting disease patterns in psoriasis and atopic dermatitis.ArchDermatolRes 1987;279(suppl):S48S51.

71 Nomura I, Goleva E, Howell MD, Hamid QA, Ong PY, Hall CF, Darst MA, Gao B, Boguniewicz M, Travers JB, Leung DY: Cytokine milieu of atopic dermatitis, as compared to psoriasis, skin prevents induction of innate immune response genes. J Immunol 2003;171:3262-3269.

72 Ong PY, Ohtake T, Brandt C, Strickland I, Boguniewicz M, Ganz T, Gallo RL, Leung DY: Endogenous antimicrobial peptides and skin infections in atopic dermatitis. $\mathrm{N}$ Engl J Med 2002;347:1151-1160.

73 Liu AY, Destoumieux D, Wong AV, Park CH, Valore EV, Liu L, Ganz T: Human beta-defensin-2 production in keratinocytes is regulated by interleukin-1, bacteria, and the state of differentiation. J Invest Dermatol 2002; 118:275-281.

74 Erdag G, Morgan JR: Interleukin-1alpha and interleukin-6 enhance the antibacterial properties of cultured composite keratinocyte grafts. Ann Surg 2002;235:113-124.

75 Lande R, Gregorio J, Facchinetti V, Chatterjee B, Wang YH, Homey B, Cao W, Wang YH, Su B, Nestle FO, Zal T, Mellman I, Schröder JM, Liu YJ, Gilliet M: Plasmacytoid dendritic cells sense self-DNA coupled with antimicrobial peptide. Nature 2007;449. 564-569.
76 Blount BW, Pelletier AP: Rosacea: a common yet commonly overlooked condition. Am Fam Physician 2002;66:435-440.

77 Berg M, Liden S: An epidemiological study of rosacea. Acta Derm Venereol 1989;69:419423.

78 Eiseman AS: The ocular manifestations of atopic dermatitis and rosacea. Curr Allergy Asthma Rep 2006;6:292-298.

79 Korting HC, Schöllmann C: Tetracycline actions relevant to rosacea treatment. Skin Pharmacol Physiol 2009;22:287-294.

80 Schauber J, Ruzicka T, Rupec RA: Cathelicidin LL-37. Ein zentraler Faktor in der Pathogenese inflammatorischer Dermatosen. Hautarzt 2008;59:72-74

81 Yamasaki K, Di Nardo A, Bardan A, Murakami $\mathrm{M}$, Ohtake $\mathrm{T}$, Coda $\mathrm{A}$, Dorschner RA, Bonnart C, Descargues P, Hovnanian A, Morhenn VB, Gallo RL: Increased serine protease activity and cathelicidin promotes skin inflammation in rosacea. Nat Med 2007;13:975-980

82 Degitz K,Placzek M, Borelle C, Plewig G: Pathophysiologie der Akne. J Dtsch Dermatol Ges 2007;5:316-323.

83 Nagy I, Pivarcsi A, Koreck A, Szell M, Urban E, Kemeny L: Distinct strains of Propionibacterium acnes induce selective human beta-defensin- 2 and interleukin-8 expression in human keratinocytes through toll-likereceptors. J Invest Dermatol 2005;124:931938 .

84 Sader HS, Fedler KA, Rennie RP, Stevens S, Jones RN: Omiganan pentahydrochloride (MBI 226), a topical 12-amino-acid cationic peptide: spectrum of antimicrobial activity and measurements of bactericidal activity. Antimicrob Agents Chemother 2004;48: 3112-3118.

85 Melo MN, Dugourd D, Castanho MA: Omiganan pentahydrochloride in the front line of clinical applications of antimicrobial peptides. Recent Pat Antiinfect Drug Discov 2006;1:201-207.

86 Cork MJ, Danby SG, Vasiloupoulos Y, Hadgraft J, Lane E, Moustafa M, Guy RH, MacGowan AL, Tazi-Ahnini R, Ward SJ: Epidermal barrier dysfunction in atopic dermatitis. J Invest Dermatol 2009;129:1892-1908.

87 Boguniewicz M, Leung DYM: Recent insights into atopic dermatitis and implications for management of infectious complications. J Allergy Clin Immunol 2010;125: 4-13.

88 de Jongh GJ, Zeeuwen PL, Kucharekova M, Pfundt R, van der Valk PG, Blokx W, Dogan A, Hiemstra PS, van de Kerkhof PC, Schalkwijk J: High expression levels of keratinocyte antimicrobial proteins in psoriasis compared with atopic dermatitis. Invest Dermatol 2005; 125:1163-1173. 
89 Guttman-Yassky E, Lowes MA, FuentesDuculan J, Zaba LC, Cardinale I, Nograles KE, Khatcherian A, Novitskaya I, Carucci JA, Bergman R, Krueger JG: Low expression of the IL-23/Th17 pathway in atopic dermatitis compared to psoriasis. J Immunol 2008; 181:7420-7427.

90 Howell MD: The role of human beta defensins and cathelicidins in atopic dermatitis. Curr Opin Allergy Clin Immunol 2007;7: 413-417.

91 Gläser R, Meyer-Hoffert U, Harder J, Cordes J, Wittersheim M, Kobliakova J, FölsterHolst R, Proksch E, Schröder JM, Schwarz $\mathrm{T}$ : The antimicrobial protein psoriasin (S100A7) is upregulated in atopic dermatitis and after experimental skin barrier disruption. I Invest Dermatol 2009;129:641-649.

92 Harder J, Dressel S, Wittersheim M, Cordes J, Meyer-Hoffert U, Mrowietz U, FölsterHolst R, Proksch E, Schröder JM, Schwarz T, Gläser R: Enhanced expression and secretion of antimicrobial peptides in atopic dermatitis and after superficial skin injury. J Invest Dermatol 2010;130:1355-1364.

93 Koczulla R, von Degenfeld G, Kupatt C, Krötz F, Zahler S, Gloe T, Issbrücker K, Unterberger P, Zaiou M, Lebherz C, Karl A, Raake P, Pfosser A, Boekstegers P, Welsch U, Hiemstra PS, Vogelmeier C, Gallo RL, Clauss M, Bals R: An angiogenic role for the human peptide antibiotic LL-37/hCAP-18. J Clin Invest 2003;111:1665-1672.

94 Oono T, Huh WK, Shirafuji Y, Akiyama H, Iwatsuki K: Localization of human beta-defensin-2 and human neutrophil peptides in superficial folliculitis. Br J Dermatol 2003; 148:188-191.
95 Kreuter A, Huyn J, Skrygan M, Sommer A, Bastian A, Altmeyer P, Gambichler T: Ultraviolet A1-induced downregulation of human beta-defensins and interleukin- 8 correlates with clinical improvement in localized scleroderma. Br J Dermatol 2006; 155:600-607.

96 Escher N, Spies-Weisshart B, Kaatz M, Melle C, Bleul A, Driesch D, Wollina U, von Eggeling F: Identification of HNP3 as a tumour marker in CD4+ and CD4- lymphocytes of patients with cutaneous T-cell lymphoma. Eur J Cancer 2006;42:249-255.

97 Conner K, Nern K, Rudisill J, O’Grady T, Gallo RL: The antimicrobial peptide LL-37 is expressed by keratinocytes in condyloma acuminatum and verruca vulgaris. J Am Acad Dermatol 2002;47:347-350.

98 Brogden NK, Brogden KA: Will new generations of modified antimicrobial peptides improve their potential as pharmaceuticals? Int J Antimicrob Agents 2011;38 217-225.

99 Steinstraesser L, Kraneburg U, Jacobsen F Al-Benna S: Host defense peptides and their antimicrobial-immunomodulatory duality. Immunobiology 2011;216:322-333.

100 Guarna M, Coulson M, Rubinchik E: Antiinflammatory activity of cationic peptides: application to the treatment of acne vulgaris. FEMS Microbiol Lett 2006;257:1-6.

101 Risso A, Zanetti M, Gennaro R: Cytotoxicity and apoptosis mediated by two peptides of innate immunity. Cell Immunol 1998; 189:107-115.

102 Steinstraesser L, Burghard O, Menzek J, Fan MH, Merry A, Remick DI, Su GL, Steinau HU, Wang SC: Protegerin-1 increases bacterial clearance in sepsis but decreases survival. Crit Care Med 2003;31 221-226.
103 Jacobsen F, Mohammadi-Tabrisi A, Hirsch T, Mittler D, Mygind PH, Sonksen CP, Raventos D, Kristensen HH, Gatermann S, Lehnhardt M, Daigeler A, Steinau HU, Steinstraesser L: Antimicrobial activity of the recombinant designer host defence peptide P-novispirin G10 in infected fullthickness wounds of porcine skin. J Antimicrob Chemother 2007;59:493-549.

104 Li Q, Zhou Y, Dong K, Guo X: Potential therapeutic efficacy of a bacterial-immunomodulatory fusion peptide against methicillin-resistant Staphylococcus aureus skin infection. Applied Microbiol Biotechnol 2010;86:305-309.

105 Ciornei CD, Sigurdadottir T, Schmidtchen A, Bodelsson M: Antimicrobial and chemoattractant activity, lipopolysaccharide neutralization, cytotoxicity, and inhibition by serum of analogs of human cathelicidin LL-37. Antimicrob Agents Chemother 2005;49:2845-2850.

106 Sigurdadottir T, Andersson P, Davoudi M, Malmsten M, Schmidtchen Al, Bodelsson $\mathrm{M}$ : In silico identification and biological evaluation of antimicrobial peptides based on human cathelicidin LL-37. Antimicrob Agents Chemother 2006;50:2983-2989.

107 Shai Y: From innate immunity to de-novo designed antimicrobial peptides. Curr Pharm Des 2002;8:715-725.

108 Giacometti A, Cirioni O, Ghiselli R, Mocchegiani F, Orlando F, Silvestri C, Bozzi A, Di Giulio A, Luzi C, Mangoni ML, Barra D, Saba V, Scalise G, Rinaldi AC: Interaction of antimicrobial peptide temporin $\mathrm{L}$ with lipopolysaccharide in vitro and in experimental rat models of septic shock caused by gram-negative bacteria. Antimicrob Agents Chemother 2006;50:2478-2486. 